\title{
Review
}

\section{The Journal of Irreproducible Results*}

Most researchers must at some time have spent a few idle moments contemplating using their hard-earned experience on projects of slightly less academic value. Perhaps the idea of cognitive therapy for weeping willows appeals, or maybe neurotransmitters can be modelled using a billiard ball, an apricot and a tram ticket. Most such thoughts are quickly forgotten. Some might end up on the backs of envelopes, as hastily sketched research protocols. Few are written up, but The Journal of Irreproducible Results exists to bring the fruits of these dubious labours to a wider audience.

JIR has been going for over 35 years, and has built up an impressive staff (including two circulation managers: clockwise and counterclockwise) and Editorial Board, covering everything from Allergy to Zoology, by way of Bureaucratic Affairs, Developmental Psychology and Marine Geology. This diversity is reflected in the papers. Recent issues have covered feline reactions to photos of bearded men (cats do not like men with long dark beards, but are indifferent to other types), the taxonomy of ceiling tiles (three main species were found; the four different subspecies of each proved, on closer inspection, to be simple rotations of a single gentotype), and a calculation of the expected date of the heat death of the universe by extrapolating from the time taken for an office desktop to reach maximum entropy.

One function of journals is to promote research as well as report it, and special issues such as that on jelly can help do this. In a commendably multidisciplinary effort, the issue discusses such diverse features of jelly as how it killed the dinosaurs, how to achieve uniform distribution of canned fruit in it using isoelectric focusing electrophoresis, its transformational-generative grammar, and its uses as housing insulation and in preserving books (treating all the pages with yellow jelly not only prolongs the book's life, but allows it to be advertised as pre-highlighted).

* Subscription information: Journal of Irreproducible Results, Blackwell Scientific Publications, Inc., Three Cambridge Center, Cambridge, MA 02142, USA (telephone $8007596102 ; 617225$ 0401).
As you might expect from a journal with such a broad brief, psychiatry is not neglected. There is a useful review of the evidence for a gene which predisposes individuals to behave chronically in an obnoxious, boorish, selfish, overbearing, and generally offensive manner (the AH gene). An obituary of Dr Bruno Bruttelheim, noted advocate of the use of environmental colour to influence patients' moods, does not attempt to gloss over his tendency to roller his patients with latex paint (blue for depression, brown for lethargy, black for suicidal tendencies). Elsewhere, an appreciation of Howard J. Brannd, father of psychoterminology, explains how this television repair engineer revolutionised the language of psychotherapy, bringing across terms like 'process', 'resonance', and 'saturation', and modifying others such as 'negative transmission' to 'negative transference'.

Journals would be dull affairs indeed without a sprinkling of special features to liven the pages. JIR scores well in this respect. Nobel Laureates are asked penetrating questions about their views on chewing gum. The 'JIR Recommends' section points the way to such gems in the literature as 'Worms in Space' and 'What bird did that?' The 'Elegant Results' column summarises important research findings from journals such as Women and Guns and The New Yorker. Did you know, for example, that chemists at Le Meridien are developing techniques to purify luxury? Or that Maker's Mark Distillery have been investigating the dreams of frogs? It is remarkable how easily such work is overlooked, simply because the reports are presented in a commercial context.

JIR serves two valuable purposes. Firstly, it is a useful reminder that scientific journals should be read in an open and highly critical frame of mind. Appearance in print cannot guarantee the validity of a piece of work. Secondly, it is extremely funny, and for this reason alone it deserves a wide circulation.

DAVE JAGo

Publications Manager

The Royal College of Psychiatrists 